\title{
Cardiovascular risk among South Asians living in Canada: a systematic review and meta-analysis
}

\author{
Ayesha Rana BHSc, * Russell J. de Souza ScD RD, * Sujane Kandasamy BSc BA, Scott A. Lear PhD, \\ Sonia S. Anand MD PhD \\ *Both authors contributed equally to this work
}

\section{Abstract}

Background: South Asians represent about 3\% of the Canadian population and have a higher burden of certain cardiovascular risk factors and cardiovascular disease (CVD) compared with white people. The objective of this study was to review the literature to compare cardiovascular risk factors and disease management practices among adult South Asian and white Canadians.

Methods: We searched MEDLINE, Embase, Cochrane and Cumulative Index to Nursing and Allied Health Literature databases from their inception through Feb. 17, 2014 and the reference lists of the selected articles. English-language studies of interventions and observational studies of biological mechanisms underlying CVD risk in South Asians conducted in Canada were eligible for inclusion. Where appropriate, we used random-effects meta-analyses to integrate results comparing the CVD risk profiles of South Asian and white Canadians.

Results: We included 50 articles ( $n=5805313$ individuals) in this review. Compared with white Canadians, South Asian Canadians had a higher prevalence and incidence of CVD, an increased prevalence of diabetes (odds ratio [OR] 2.25, 95\% confidence interval $[\mathrm{Cl}] 1.81$ to $2.80, p<0.001$ ) and hypertension (OR $1.11,95 \% \mathrm{Cl} 1.02$ to $1.22, p=0.02$ ), lower high-density lipoprotein cholesterol levels (mean difference $-0.19 \mathrm{mmol} / \mathrm{L}, 95 \% \mathrm{Cl}-0.25$ to $-0.13 \mathrm{mmol} / \mathrm{L}, p<0.001$ ) and a higher percentage of body fat (men: absolute mean difference $3.23 \%, 95 \% \mathrm{Cl} 0.83 \%$ to $5.62 \%, p=0.008$; women: absolute mean difference $4.09 \%, 95 \% \mathrm{Cl} 3.46 \%$ to $4.72 \%$, $p<0.001)$. South Asian people are also more sedentary, consume higher levels of carbohydrates and are less likely to smoke tobacco (OR $0.38,95 \% \mathrm{Cl} 0.24$ to $0.60, p<0.001]$ ) than white Canadians. No differences in access to diagnostic tests, outcomes following cardiovascular surgery or use of cardiac rehabilitation programs were apparent.

Interpretation: Compared with white people, South Asian people living in Canada have a higher prevalence and incidence of CVD and possess a unique cardiovascular risk profile.

lmost 1 million South Asian people live in Canada ( $3 \%$ of the Canadian population) and represent one of the country's fastest growing ethnic groups. ${ }^{1}$ Of the approximately $70 \%$ born outside Canada, $75 \%$ immigrated to Canada in the last 20 years. ${ }^{1}$

Evidence collected over the last 20 years suggests that rates of cardiovascular disease (CVD) and health behaviours vary among ethnic groups in Canada and that adoption of health behaviours typical of Western countries may promote the development of cardiometabolic risk factors among various ethnic groups. ${ }^{2}$ Initial research suggests that one group in particular, South Asians (i.e., people originating from India, Pakistan, Sri Lanka, Nepal and Bangladesh) have higher CVD rates than other groups, ${ }^{2-5}$ and these differences persist in their offspring. ${ }^{6}$ South Asian people also have more severe CVD, present with the disease at younger ages and, in some contexts, have differential access to diagnostic and treatment services compared with non-South Asian people. ${ }^{7-9}$

The health of the South Asian population is of great importance to Canadian society, and it is important to quantify their risk of CVD to inform health promotion strategies. We systematically reviewed the literature comparing South Asian people with white people living in Canada with respect to CVD risk factors, management, access to diagnostic testing and adherence to cardiac rehabilitation programs.

Competing interests: None declared.

This article has been peer reviewed.

Correspondence to: Sonia Anand, anands@mcmaster.ca

CMAJ Open 2014.DOI:10.9778/cmajo.20130064 


\section{Methods}

\section{Search strategy and selection}

In consultation with an information specialist, we developed search terms for MEDLINE, Embase, the Cumulative Index to Nursing and Allied Health Literature and the Cochrane Registry databases to identify human studies reporting associations among South Asian ethnicity, CVD risk factors and CVD. The initial search (conducted May 21, 2013) captured articles from database inception through May 2013; at the request of the CMAf Open editors, the search was updated through to Feb. 17, 2014 (Appendix 1, available online at www.cmajopen.ca/content/2/3/E183/suppl/DC1). Three investigators (A.R., R.dS. and S.S.A.) each screened a third of the titles and abstracts of the studies identified in the electronic search to arrive at a list of articles for full-text review. The same 3 reviewers assessed the eligibility of these fulltext articles. Disagreements were resolved by discussion and consensus. Studies that were not published as full reports, such as conference abstracts and letters to the editor, were excluded.

Pairs of reviewers independently extracted study design characteristics and main results from each study. Missing variance measures were imputed using published formulae. ${ }^{10}$

\section{Quality assessment and meta-analysis}

Three reviewers independently assessed the risk of bias of each of the included studies on a scale from 1 (high risk) to 7 (low risk) and discussed their assessments to achieve consensus. A score for quality, modified from the NewcastleOttawa scale, ${ }^{11}$ was used to assess appropriateness of research design, recruitment strategy, response rate, representativeness of sample, objectivity/reliability of outcome determination, power calculation provided, and appropriate statistical analyses. Inverse variance random-effects weighted meta-analysis was done for both continuous and dichotomous outcomes (Review Manager, v. 5.2). The summary effect measures were the mean difference (MD) and $95 \%$ confidence interval (CI) for continuous outcomes: systolic blood pressure, diastolic blood pressure, total cholesterol, low density lipoprotein (LDL) cholesterol, high density lipoprotein (HDL) cholesterol, triglycerides, fasting blood levels of insulin and glucose, homeostasis model assessment of insulin resistance, body mass index (BMI), percentage body fat, waist-to-hip ratio and C-reactive protein. For dichotomous outcomes - smoking, diabetes mellitus, hypertension and obesity - the summary effect measures were the prevalence odds ratio (OR) and $95 \%$ CIs. Age- and sex-adjusted estimates were preferred. The presence of heterogeneity was assessed using Cochran's Q test (considered significant at the $p<0.1$ level) and quantified using the $I^{2}$ statistic (ranging from $0 \%$ to $100 \%$ ) using the cut-off points for important heterogeneity described by Higgins and colleagues. ${ }^{12}$ Because of the small number of studies, the prevalence and incidence of CVD, the prevalence of impaired fasting glucose and impaired glucose tolerance and summaries of differences in lipoprotein(a), the ratio of apolipoprotein B to apolipoprotein A-1, plasminogen activator inhibitor-1, physical inactivity, dietary intake and management of CVD were reviewed but not meta-analyzed.

Heterogeneity was explored through preplanned sensitivity analyses limited to high-quality studies (quality score $\geq 5$ ) and by stratifying analyses by study type (administrative database v. cross-sectional) and sampling mechanism (random v. convenience). Heterogeneity is reported in Appendix 2, eTable 1 (www.cmajopen.ca/content/2/3/E183/suppl/DC1). Secondary analyses examining heterogeneity are reported in Appendix 2, eTable 2 and Appendix 3 (www.cmajopen.ca/content /2/3/E183/suppl/DC1).

\section{Results}

The search identified 22221 potentially relevant articles, 22116 of which were excluded after abstract review, leaving 105 for full-text review. Of these, 55 articles were excluded (Figure 1). The 50 included studies $(n=5805313$ individuals) (Appendix 4, www.cmajopen.ca/content/2/3/E183/suppl/DC1) covered a long period, 1979 to 2007. Of these studies, 21 (42\%) were cross-sectional, 24 (48\%) were retrospective chart or database reviews, 2 (4\%) were prospective cohort studies, $2(4 \%)$ were descriptive studies and $1(2 \%)$ was a case-control study.

\section{Prevalence and incidence of heart disease}

Compared with white people, South Asian people in Canada had a higher age-standardized incidence of acute myocardial infarction (MI): 4.97 events per 1000 population per year among South Asian men versus 3.29 among white men $(p<0.001) ; 2.35$ events per 1000 population per year among South Asian women versus 1.53 among white women $(p=0.01) \cdot{ }^{13}$ The prevalence of CVD (defined as a history of MI, angina, silent MI, percutaneous transluminal coronary angioplasty, coronary artery bypass grafting or stroke) was also higher among South Asian people: $5.7 \%$ to $10.0 \%$ versus $5.4 \%$ to $5.7 \%$ among white people $(p<0.05)^{3,4,14}$ (see Appendix 3 for details). Furthermore, from 1979 to 1993, sex-standardized rates of mortality from coronary disease were higher among South Asian people compared with white people: men, $42 \%$ versus $29 \%(p<0.001)$; women, $29 \%$ versus $19 \%(p<0.001) .{ }^{15}$

\section{Risk factors}

\section{BMI and abdominal obesity}

Although the BMIs of South Asian Canadians were similar to those of white Canadians (men: MD $-0.52,95 \%$ CI -1.51 to $0.47, p=0.31$; women: $\mathrm{MD}-0.14,95 \% \mathrm{CI}-0.99$ to $0.74, p=0.77$ ) (Figure 2), ${ }^{3,14,16-19}$ South Asian people had a higher percentage body fat compared with white people (Figure 3) $16,17,20$ (men: absolute MD 3.23\%, 95\% CI $0.83 \%$ to $5.62 \%, p=0.008$; women: absolute MD $4.09 \%$, $95 \%$ CI $3.46 \%$ to $4.72 \%, p<0.001$ ) and South Asian women had a higher waist-to-hip ratio ${ }^{3,16-18,20}$ (MD $0.02,95 \%$ CI 0.01 to $0.04, p=0.005)$. The prevalence of obesity $(\mathrm{BMI} \geq 30)^{4,8,21}$ 
was lower among South Asian people (OR 0.62, 95\% CI 0.40 to $0.96, p=0.03)$. No significant differences were found in waist-to-hip ratio ${ }^{3,16-18,20}$ between South Asian and white men or in sex-specific waist circumference ${ }^{14,17-20,22,23}$ (Appendix 2, eTable 1).

\section{Fat distribution}

South Asian men had a higher mean total abdominal adipose tissue than white men $\left(439.7 \mathrm{~cm}^{2}\right.$, standard deviation [SD] $169.5 \mathrm{~cm}^{2}$ v. $369.1 \mathrm{~cm}^{2}$, SD $\left.164.0 \mathrm{~cm}^{2}, p=0.003\right)$, although there was no difference between South Asian and white women. ${ }^{24,25}$ Further-more, South Asian people had less subcutaneous adipose tissue (as a percentage of total abdominal adipose tissue) than white people (MD $-2.94 \%, 95 \%$ CI $-5.56 \%$ to $-0.32 \%, p<0.05$ ) and $17 \%$ more deep subcutaneous and visceral fat relative to superficial subcutaneous fat ${ }^{20,26}$ (Appendix 3).

\section{Type 2 diabetes and impaired glucose tolerance}

Compared with white people, South Asian people had a 2-fold increase in point prevalence of diabetes ${ }^{3,4,9,14,23,27-36}$ (OR 2.25, $95 \%$ CI 1.81 to $2.80, p<0.001$ ) (Figure 4), an increased incidence of diabetes (new cases between 1993 and 2007), ,22,37-40 a greater prevalence of impaired glucose tolerance ${ }^{3,36}$ (Appendix 3), higher fasting insulin levels ${ }^{3,18-20,24,41}$ (MD $19.16 \mathrm{pmol} / \mathrm{L}, 95 \%$ CI 13.86 to $24.46 \mathrm{pmol} / \mathrm{L}, p<0.001)$ and increased insulin resistance by homeostasis model assessment ${ }^{19,20,41-43}$ (MD 0.75, 95\% CI 0.33 to $1.17, p<0.001)$. No differences in fasting glucose levels ${ }^{3,18-20,24,41}$ were observed (Appendix 2, eTables 1 and 2).

\section{Blood pressure, hypertension}

South Asian people had a lower systolic blood pressure than white people (MD $-1.96 \mathrm{~mm} \mathrm{Hg}$, 95\% CI -3.76 to $-0.16 \mathrm{~mm}$ $\mathrm{Hg}, p=0.03$ ) but similar diastolic blood pressure $3,18-20,24,41$ (Appendix 2, eTables 1 and 2). However, South Asian people

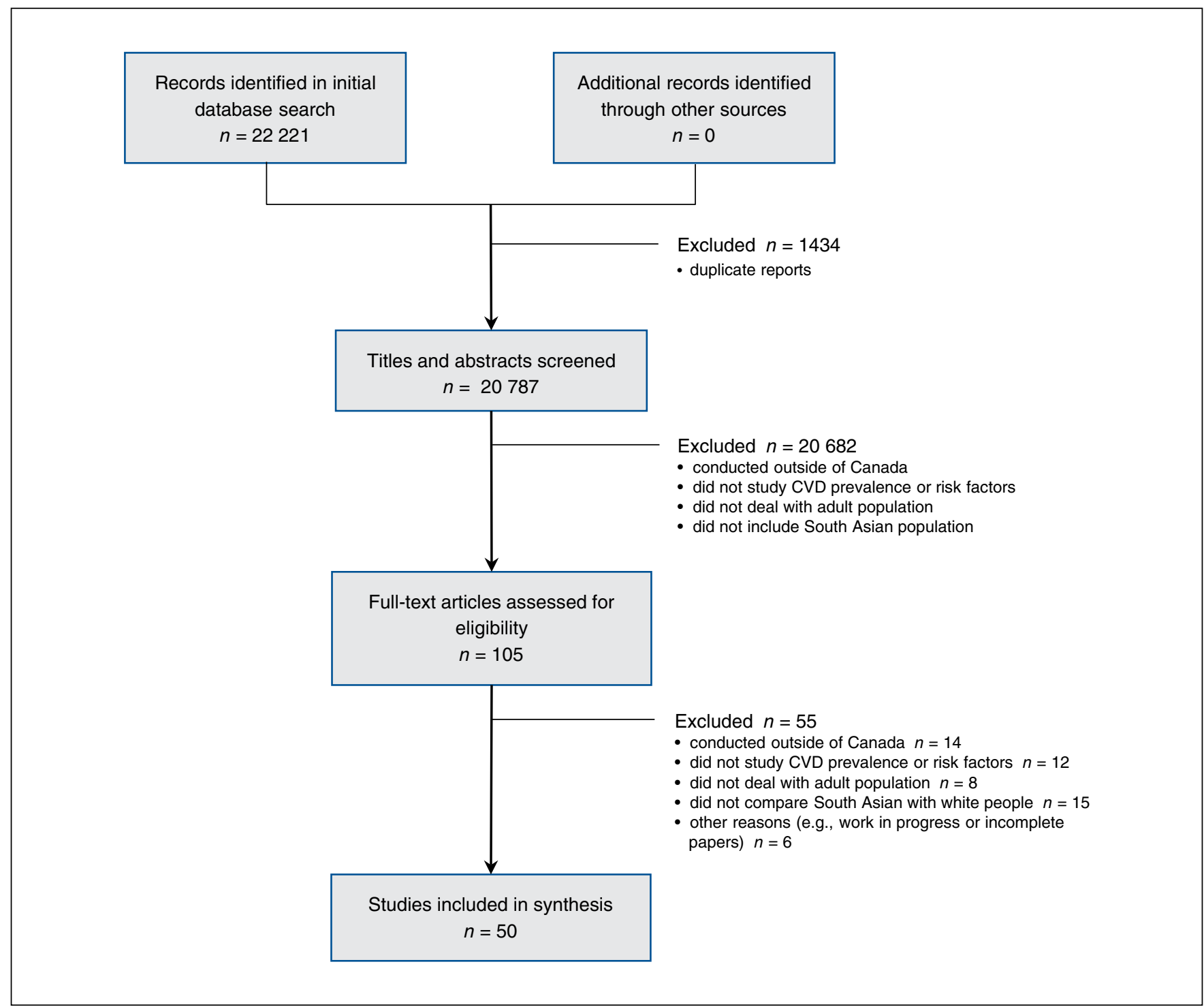

Figure 1: Selection of studies comparing cardiovascular risk factor and disease management practices among adult South Asian and white Canadians. CVD = cardiovascular disease. 
were more likely to have hypertension compared with white people $3,4,9,14,27,28,31,32,34-36,41,44$ (OR $1.11,95 \%$ CI 1.02 to 1.22 , $p=0.02)$.

\section{Lipid levels}

South Asian people had lower HDL cholesterol ${ }^{3,16,18-20,24,41}$ (MD $-0.19 \mathrm{mmol} / \mathrm{L}, 95 \% \mathrm{CI}-0.25$ to $-0.13 \mathrm{mmol} / \mathrm{L}, p<0.001)$ and apolipoprotein A-1 levels, 3,45 and a higher total cholesterol to HDL cholesterol ratio ${ }^{16,18-20,22,24}$ (MD $0.65,95 \%$ CI 0.28 to 1.01 , $p=0.0006$ ), triglyceride levels $\mathrm{s}^{3,18-20,24,41}$ (MD $0.20 \mathrm{mmol} / \mathrm{L}, 95 \%$
CI 0.02 to $0.37 \mathrm{mmol} / \mathrm{L}, p=0.03)$, lipoprotein $(\mathrm{a})^{3}$ and a ratio of apolipoprotein $\mathrm{B}$ to apolipoprotein $\mathrm{A}-1^{16}$ than white people (Appendix 3). There were no significant differences in total cholesterol $^{3,16,18,19,24,41}$ or LDL cholesterol ${ }^{3,18-19,24,41}$ (Appendix 2, eTables 1 and 2).

\section{Smoking}

South Asian people were $60 \%$ less likely to smoke tobacco than white people (OR $0.38,95 \%$ CI 0.24 to 0.60 , $p<0.001) .3,4,7,9,14,16,20,21,28-30,32-36,46$

\section{A. Men}

Study

\section{Random sampling}

Anand et al. $2000^{3}$

Subtotal $(95 \% \mathrm{Cl})$

Heterogeneity: Not applicable

\section{Non-random sampling}

Lear et al. $2003^{18}$

Smith et al. $2006^{16}$

Lear et al. 200917

Foulds et al. $2012^{14}$

García-Bailo et al. $2013^{19}$

Subtotal $(95 \% \mathrm{Cl})$

Heterogeneity: $I^{2}=70 \%$

Total $(95 \% \mathrm{Cl})$

Heterogeneity: $I^{2}=76 \%$

Test for subgroup differences: $I^{2}=88.1 \%$

$\begin{array}{lllrc}25.9(3.8) & 34 & 25.7(3.5) & 35 & 0.2(-1.5 \text { to } 1.9) \\ 28.31(4.26) & 54 & 26.6(5.1) & 32 & 1.7(-0.4 \text { to } 3.8) \\ 27.9(4.5) & 105 & 27.7(4.7) & 101 & 0.2(-1.1 \text { to } 1.5) \\ 26.7(3.3) & 116 & 28.1(4.6) & 1463 & -1.4(-2.1 \text { to }-0.8) \\ 23.86(3.91) & 63 & 24.1(3.4) & 218 & -0.2(-1.3 \text { to } 0.8) \\ & 372 & & 1849 & -0.1(-1.1 \text { to } 0.9)\end{array}$

\section{B. Women}

Study
Random sampling
Anand et al. $2000^{3}$
Subtotal $(95 \% \mathrm{Cl})$
Heterogeneity: Not applicable

South Asian

Mean BMI (SD)

$26.5(6.1)$

155

$26.6(5.8)$

White

n $\overline{\text { Mean BMI (SD) }}$

$n$

Heterogeneity: Not applicable

\section{Non-random sampling}

Lear et al. $2003^{18}$

Smith et al. $2006^{16}$

Lear et al. 200917

Foulds et al. $2012^{14}$

García-Bailo et al. $2013^{19}$

Subtotal $(95 \% \mathrm{Cl})$

Heterogeneity: $I^{2}=67 \%$

Total $(95 \% \mathrm{Cl})$

Heterogeneity: $I^{2}=59 \%$

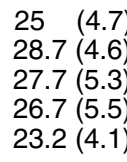

$23.2(4.1)$

Test for subgroup differences: $I^{2}=0 \%$
Mean difference $(95 \% \mathrm{Cl})$

Mean difference $(95 \% \mathrm{Cl})$

$-2.4(-3.6$ to -1.2$)$

$-2.4(-3.6$ to -1.2$)$

$-0.1(-1.4$ to 1.2$)$

$169-0.1(-1.4$ to 1.2$)$

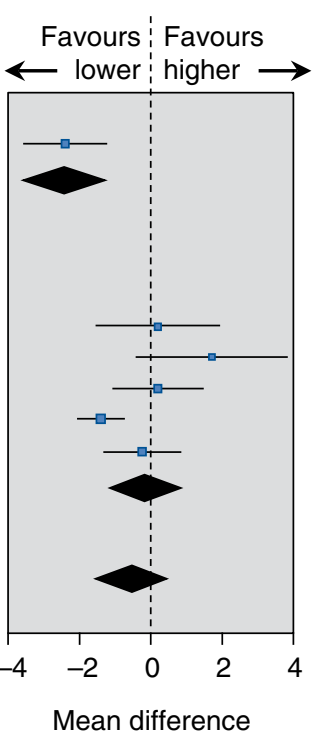

$(95 \% \mathrm{Cl})$

Favours Favours

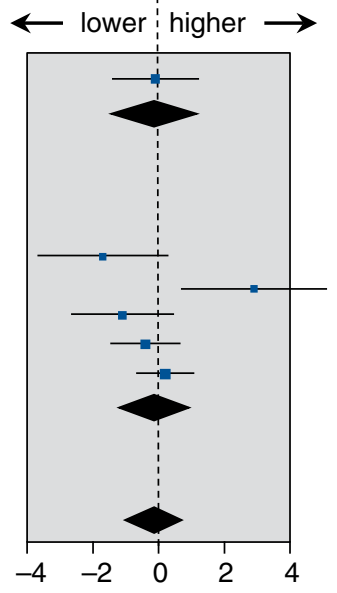

Mean difference $(95 \% \mathrm{Cl})$

Figure 2: Meta-analysis of studies evaluating differences in body mass index between South Asian and white Canadian men (A) and women (B). A mean difference greater than zero indicates higher BMI among South Asian people. BMI = body mass index, $\mathrm{Cl}=\mathrm{confidence}$ interval, $\mathrm{SD}$ = standard deviation. 


\section{Other}

Limited data exist on novel markers of vascular risk, ${ }^{3,18,20,24,47}$ socioeconomic status and psychosocial stress, ${ }^{4,48}$ food intake, ${ }^{2,21,30,49}$ and physical activity, ${ }^{14,20,30,49-52}$ or on participation in cardiac rehabilitation programs ${ }^{28,53,54}$ (Appendix 3).

\section{Diagnosis, management and outcomes}

South Asian people appeared to delay presentation to hospital with symptoms of acute MI. The median time from symptom onset to presentation to a hospital in a southern Ontario sample $^{9}$ was about 1 hour longer for South Asian people than white people (3.92 h v. $3.08 \mathrm{~h}, p=0.04)$. Once in hospital, however, South Asian people and white people had similar access to diagnostic procedures and interventions ${ }^{2,7,8,27}$ for CVD, although there was some practice and outcome variation between provinces (Appendix 3). Following hospital admission for acute coronary syndrome, South Asians had higher short-term $(<1 \mathrm{yr})$ recurrent event rates, including readmission to hospital and recurrent angina, compared with white people..$^{7,27,55-57}$ However, short- ${ }^{7-9,27,32,55,58}$ and long-term mortality $^{7,27,31,32,34,51}$ after MI appeared to be similar among South Asian and white people (Appendix 3).

\section{Interpretation}

This review shows that South Asian people living in Canada have a higher prevalence and incidence of CVD compared with white people $\mathrm{e}^{2,15}$ and possess a unique CVD risk profile. However, some inter-study variation exists in these results; we attribute this to differences in classification of ethnicity (i.e., self-report v. direct assessment v. surname classification), heterogeneity of South Asian populations (i.e., Pakistani v. Indian v. Bangladeshi) and differences in classification of outcomes (self-report v. health administrative data). This variation emphasizes the need to develop a standardized surveillance system for non-communicable diseases, such as CVD, cancer and lung diseases, by ethnic group in Canada. ${ }^{59}$ Such a system would generate information that would help shape health services, policies and programs aimed at particularly high-risk ethnic groups.

\section{Explanation and comparison with other studies}

Compared with white people, South Asian people living in Canada have a higher prevalence of hypertension; twice the prevalence of type 2 diabetes; greater insulin resistance; a

A. Men

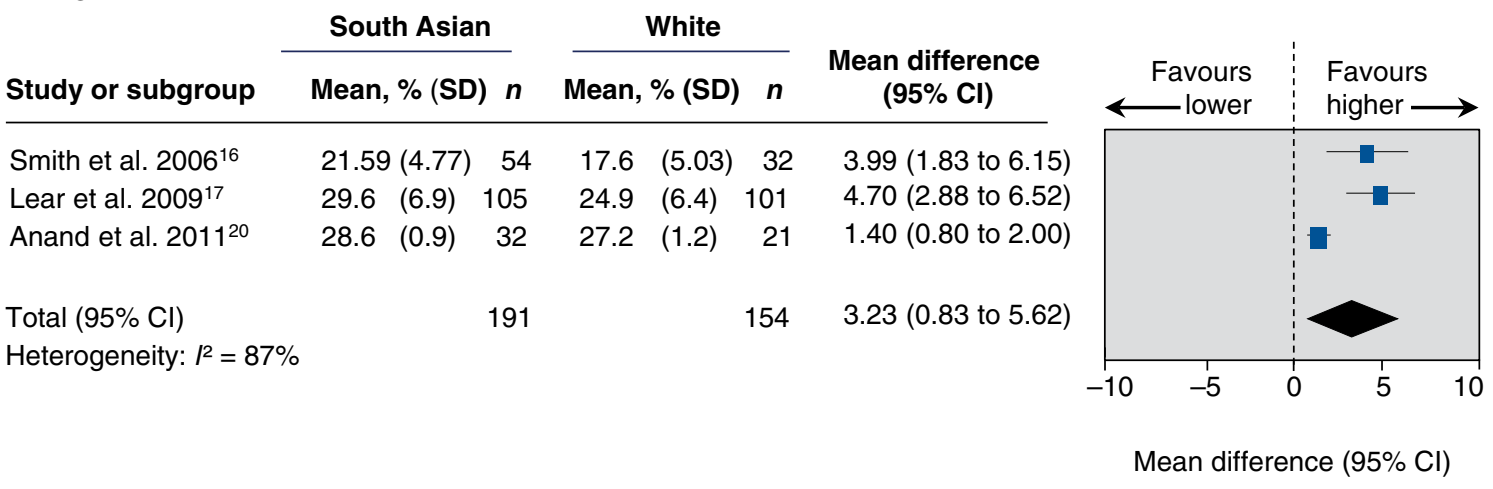

\section{B. Women}

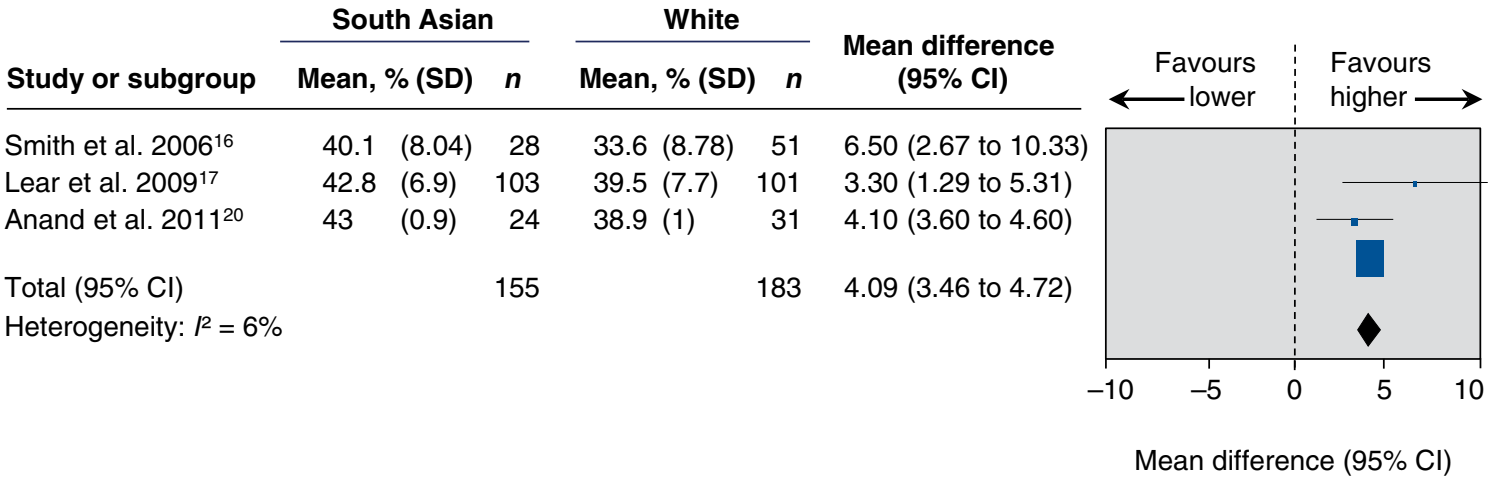

Figure 3: Meta-analysis of studies evaluating differences in percentage body fat between South Asian and white Canadian men (A) and women (B). A mean difference greater than zero indicates higher percentage body fat among South Asian people. $\mathrm{Cl}=\mathrm{confidence}$ interval, $\mathrm{SD}=\mathrm{stan}-$ dard deviation. 
higher percentage of body fat; higher visceral adiposity; a higher ratio of apolipoprotein B to apolipoprotein A-1; higher carbohydrate intake; lower HDL cholesterol levels; and lower levels of physical activity, all of which contribute to the etiology of CVD in this ethnic group. However, South Asian people in Canada are less likely than white people to smoke cigarettes. The sparse data available do not support differences in total cholesterol or LDL cholesterol levels between South Asian and white Canadians.

Although South Asian Canadians have conventionally "normal" BMI ranges, they have a higher percentage of body fat, increased visceral abdominal fat and greater insulin resistance ${ }^{4,60}$ compared with white people; these findings are consistent with those of $\mathrm{US}^{61,62}$ and British ${ }^{63}$ studies of immigrant South Asian populations. Greater insulin resistance in South Asian people may result from altered levels and actions of adipokines. ${ }^{64}$ The predisposition of South Asian people to this cardiometabolic risk profile may be a result of complex biological interactions between genetic and environmental factors. A comparative study showed that a greater proportion of newborns in South India have excessive body fat and higher umbilical cord blood insulin compared with white babies born in the United Kingdom, ${ }^{65}$ which suggests that insulin resistance develops in South Asian people in early infancy and portends increased risk of diabetes and CVD. ${ }^{66}$ Despite lower BMI, waist circumference and body weight, Canadian South Asian adolescents have higher triglyceride and lower HDL cholesterol levels than white adolescents, which shows that the adverse risk factor profile develops early among South Asians. ${ }^{6}$ The South Asian Birth Cohort (START) study ${ }^{67}$ is enrolling and prospectively following 1000 South Asian babies born in southern Ontario and will

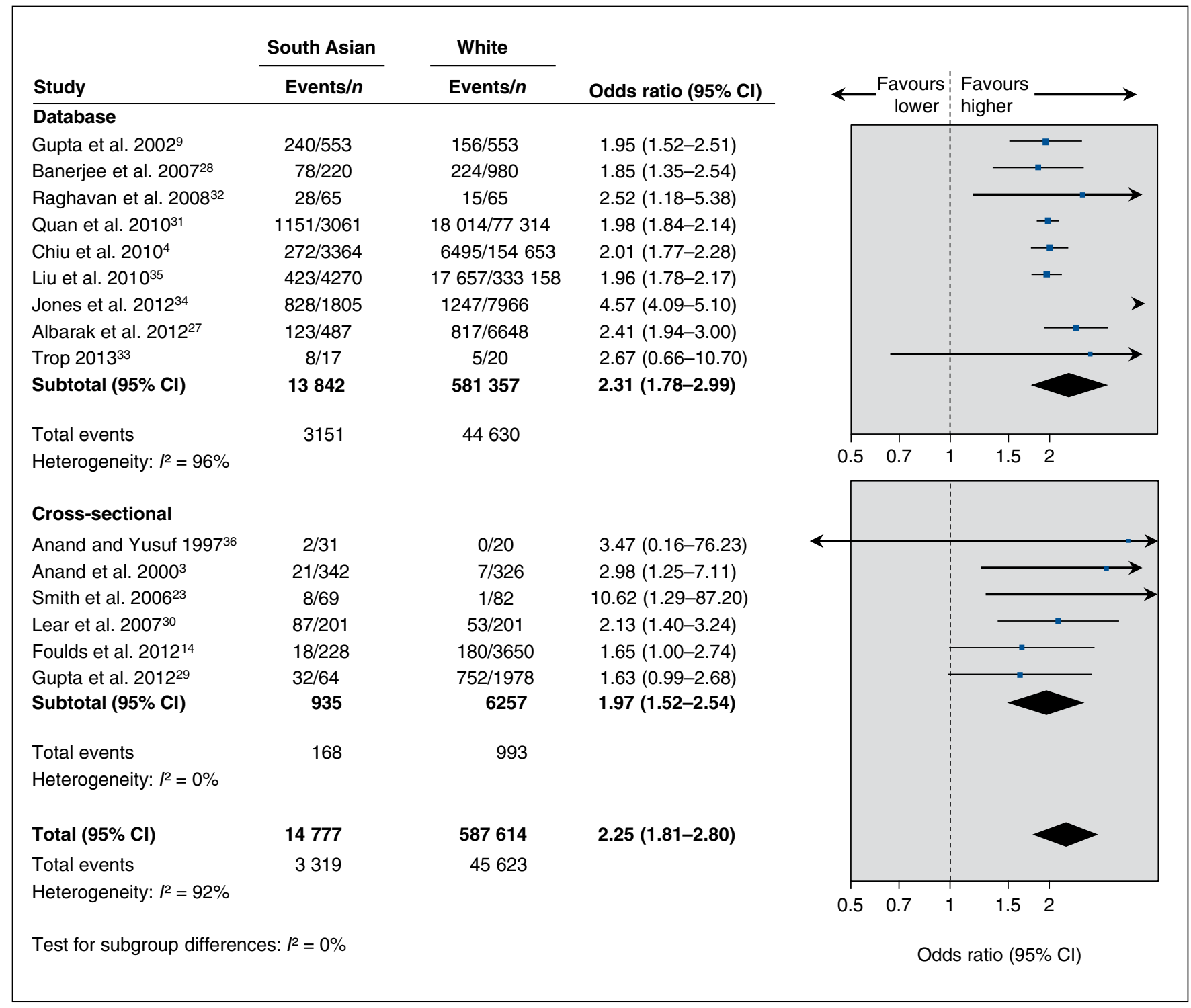

Figure 4: Meta-analysis of studies evaluating the prevalence of diabetes among South Asian versus white Canadian men (A) and women (B). An odds ratio greater than 1.0 indicates an increased risk of diabetes among South Asian people. $\mathrm{Cl}=$ confidence interval. 
provide insight into the developmental origins of CVD risk factors in this ethnic group.

Health care access, including diagnostic cardiac tests and interventions, is similar among South Asian and white people, although there are interprovincial and contextual variations. For example, South Asian people living in Alberta and British Columbia are less likely than white people to undergo angiography in under 3 hours $^{7}$ following an acute MI but are more likely to undergo angiography or cardiac catheterization at 30 days and 1 year after acute MI. ${ }^{8}$ However, a study in the greater Toronto area ${ }^{9}$ showed that South Asian and white people were equally likely to undergo angiography. We found no differences in short- or long-term mortality after MI; however, more data are required to understand the short-term clinical patterns after MI among South Asian people in Canada, as this may reflect variations in health systems. UK studies ${ }^{6-70}$ are conflicting: some show higher postoperative mortality among South Asian patients, ${ }^{70}$ whereas others show similar mortality rates between Asian and white patients. ${ }^{69}$

UK studies ${ }^{71}$ suggest that South Asian people are less adherent to cardiac rehabilitation programs than white people. Moreover, South Asian people with established CVD report worse health-related quality-of-life outcomes 1 year after angiography than white people with CVD. ${ }^{56}$ Lack of knowledge of the severity of CVD, differences in illness perception, lack of social support and stress associated with migration to Canada ${ }^{53,72-74}$ may contribute to this poor adherence.

\section{Strengths and limitations}

In this review, we pooled data from the largest studies of CVD risk in South Asian Canadians and examined sources of clinical and methodological heterogeneity. Our findings are generally consistent with $\mathrm{UK}^{68-71}$ and $\mathrm{US}^{61}$ studies. Limitations of this review include the low number of large studies of South Asian people living in Canada, the diversity of study designs and sampling schema and the lack of standardized measures of race or ethnicity (some studies based ethnicity on self-reporting, while others used an algorithm taking into account surnames and birthplace).

Substantial heterogeneity existed for most outcomes. The body of evidence posed particular problems with respect to methodologic and clinical heterogeneity because of differences in study design, sampling mechanisms and patient characteristics. The values for the $I^{2}$ statistic were frequently in the $75 \%$ to $90 \%$ range, which signifies considerable unexplained heterogeneity. To maximize our ability to synthesize the data quantitatively, we combined cross-sectional, database, prospective and case-control studies. To accommodate this, we metaanalyzed the cross-sectional (i.e., single time point) associations between ethnicity and the risk factors.

We acknowledge that the populations in the individual studies may differ with respect to clinical characteristics, including age (45 to $60 \mathrm{yr}$ ), BMI range (24 to 28 ) and waist circumference ( 80 to $100 \mathrm{~cm}$ for men and 72 to $94 \mathrm{~cm}$ for women). Heterogeneity was explored through sensitivity analyses by study quality, and subgroup analyses by study types and sampling mechanisms (Appendix 2).
Despite the high level of heterogeneity, some important consistencies were found. First, in most individual studies, the point estimates were consistent with higher insulin, triglyceride and HDL cholesterol levels and a higher ratio of total cholesterol to HDL cholesterol in South Asian people than in white people. Second, when the analyses were stratified by sampling mechanism, the unexplained heterogeneity in adiposity was reduced to almost $0 \%$. Residual differences may be attributable to lack of standardized definitions of ethnicity and varying study designs.

\section{Conclusion}

Compared with white people, South Asian people living in Canada have a higher prevalence and incidence of CVD, have twice the burden of diabetes and have a different cardiovascular risk profile. Given the increased prevalence and mortality associated with CVD among South Asian people living in Canada, etiologic studies to understand the development of these risk factors among children and youth and intervention strategies to reduce risk factors and CVD among this high-risk group are needed.

\section{References}

1. Lindsay, C. Profiles of ethnic communities in Canada: South Asian community in Canada. Ottawa: Statistics Canada; 2001.Available: www.statcan.gc.ca/pub /89-621-x/89-621-x2007006-eng.pdf (accessed 2014 Jul. 12).

2. Chiu M, Austin PC, Manuel DG, et al. Cardiovascular risk factor profiles of recent immigrants vs long-term residents of Ontario: a multi-ethnic study. Can 7 Cardiol 2012;28:20-6.

3. Anand SS, Yusuf S, Vuksan V, et al. Differences in risk factors, atherosclerosis and cardiovascular disease between ethnic groups in Canada: the Study of Health Assessment and Risk in Ethnic groups (SHARE). Lancet 2000;356:279-84.

4. Chiu M, Austin PC, Manuel DG, et al. Comparison of cardiovascular risk profiles among ethnic groups using population health surveys between 1996 and 2007. CMA7 2010;182:E301-10.

5. Bainey KR, Jugdutt BI. Increased burden of coronary artery disease in SouthAsians living in North America. Need for an aggressive management algorithm. Atherosclerosis 2009;204:1-10.

6. Vuksan V, Rogovik A, Jenkins A, et al. Cardiovascular risk factors, diet and lifestyle among European, South Asian and Chinese adolescents in Canada. Paediatr Child Health 2012;17:e1-6.

7. Khan NA, Grubisic M, Hemmelgarn B, et al. Outcomes after acute myocardial infarction in South Asian, Chinese, and white patients. Circulation 2010; 122:1570-7.

8. King KM, Khan NA, Quan H. Ethnic variation in acute myocardial infarction presentation and access to care. Am 7 Cardiol 2009;103:1368-73.

9. Gupta M, Doobay AV, Singh N, et al. Risk factors, hospital management and outcomes after acute myocardial infarction in South Asian Canadians and matched control subjects. CMA7 2002;166:717-22.

10. 7.7.3.2 Obtaining standard deviations from standard errors and confidence intervals for group means. In: Higgins JPT, Green S, editors. Cochrane handbook for systematic reviews of interventions, version 5.0.2 [updated September 2009]. London (UK): Cochrane Collaboration; 2009. Available: http://handbook. cochrane.org/chapter_7/7_7_3_2_obtaining_standard_deviations_from_standard errors and.htm (accessed 2014 Mar. 10).

11. Wells GA, Shea B, O'Connell D, et al. The Newcastle-Ottawa Scale (NOS) for assessing the quality of nonrandomised studies in meta-analyses. Ottawa: Ottawa Hospital Research Institute; 2011. Available: www.ohri.ca/programs/clinical epidemiology/oxford.asp (accessed 2014 Mar. 4).

12. Higgins JP, Thompson SG. Quantifying heterogeneity in a meta-analysis. Stat Med 2002;21:1539-58.

13. Nijjar AP, Wang H, Quan H, et al. Ethnic and sex differences in the incidence of hospitalized acute myocardial infarction: British Columbia, Canada 1995-2002. BMC Cardiovasc Disord 2010;10:38.

14. Foulds HJ, Bredin SS, Warburton DE. Greater prevalence of select chronic conditions among Aboriginal and South Asian participants from an ethnically diverse convenience sample of British Columbians. Appl Physiol Nutr Metab 2012;37:1212-21.

15. Sheth T, Nair C, Nargundkar M, et al. Cardiovascular and cancer mortality among Canadians of European, south Asian and Chinese origin from 1979 to 1993: an analysis of 1.2 million deaths. CMA7 1999;161:132-8.

16. Smith J, Cianflone K, Al-Amri M, et al. Body composition and the apoB/ 
apoA-I ratio in migrant Asian Indians and white Caucasians in Canada. Clin Sci (Lond) 2006;111:201-7.

17. Lear SA, Kohli S, Bondy GP, et al. Ethnic variation in fat and lean body mass and the association with insulin resistance. 7 Clin Endocrinol Metab 2009; 94:4696-702.

18. Lear SA, Toma M, Birmingham CL, et al. Modification of the relationship between simple anthropometric indices and risk factors by ethnic background. Metabolism 2003;52:1295-301.

19. García-Bailo B., Karmali M., Badawi A., et al. Plasma 25-hydroxyvitamin D, hormonal contraceptive use, and cardiometabolic disease risk in an ethnically diverse population of young adults. 7 Am Coll Nutr 2013;32:296-306.

20. Anand SS, Tarnopolsky MA, Rashid S, et al. Adipocyte hypertrophy, fatty liver and metabolic risk factors in South Asians: the Molecular Study of Health and Risk in Ethnic Groups (mol-SHARE). PLoS ONE 2011;6:e22112.

21. O'Loughlin J, Maximova K, Tan Y, et al. Lifestyle risk factors for chronic disease across family origin among adults in multiethnic, low-income, urban neighborhoods. Ethn Dis 2007;17:657-63.

22. Razak F, Anand S, Vuksan V, et al. Ethnic differences in the relationships between obesity and glucose-metabolic abnormalities: a cross-sectional population-based study. Int 7 Obes (Lond) 2005;29:656-67.

23. Smith J, Al-Amri M, Sniderman A, et al. Leptin and adiponectin in relation to body fat percentage, waist to hip ratio and the apoB/apoA1 ratio in Asian Indian and Caucasian men and women. Nutr Metab (Lond) 2006;3:18.

24. Lear SA, Chockalingam A, Kohli S, et al. Elevation in cardiovascular disease risk in South Asians is mediated by differences in visceral adipose tissue. Obesity (Silver Spring) 2012;20:1293-300.

25. Kohli S., Lear S. A. Differences in subcutaneous abdominal adiposity regions in four ethnic groups. Obesity (Silver Spring) 2013;21:2288-95.

26. Kohli S, Sniderman AD, Tchernof A, et al. Ethnic-specific differences in abdominal subcutaneous adipose tissue compartments. Obesity (Silver Spring) 2010;18:2177-83.

27. Albarak J, Nijjar AP, Aymong E, et al. Outcomes in young South Asian Canadians after acute myocardial infarction. Can 7 Cardiol 2012;28:178-83.

28. Banerjee AT, Gupta M., Singh N. Patient characteristics, compliance, and exercise outcomes of South Asians enrolled in cardiac rehabilitation. 7 Cardiopulm Rehabil Prev 2007;27:212-8.

29. Gupta M, Martineau P, Tran T, et al. Low-density lipoprotein cholesterol and high-sensitivity C-reactive protein lowering with atorvastatin in patients of South Asian compared with European origin: insights from the Achieve Cholesterol Targets Fast with Atorvastatin Stratified Titration (ACTFAST) study. 7 Clin Pharmacol 2012;52:850-8.

30. Lear SA, Humphries KH, Kohli S, et al. Visceral adipose tissue accumulation differs according to ethnic background: results of the Multicultural Community Health Assessment Trial (M-CHAT). Am 7 Clin Nutr 2007;86:353-9.

31. Quan H, Khan N, Li B, et al. Invasive cardiac procedure use and mortality among South Asian and Chinese Canadians with coronary artery disease. Can 7 Cardiol 2010;26:e236-42.

32. Raghavan R, Rahme E, Nedjar H, et al. Long-term prognosis of south Asians following acute coronary syndromes. Can 7 Cardiol 2008;24:585-7.

33. Trop S, Marshall JC, Mazer CD, et al. Perioperative cardiovascular system failure in South Asians undergoing cardiopulmonary bypass is associated with prolonged inflammation and increased Toll-like receptor signaling in inflammatory monocytes. 7 Surg Res 2014;187:43-52.

34. Jones DA, Rathod KS, Sekhri N, et al. Case fatality rates for South Asian and Caucasian patients show no difference 2.5 years after percutaneous coronary intervention. Heart 2012;98:414-9.

35. Liu R, So L, Mohan S, et al. Cardiovascular risk factors in ethnic populations within Canada: results from national cross-sectional surveys. Open Med 2010;4:e143-53.

36. Anand SS, Yusuf S. Risk factors for cardiovascular disease in Canadians of South Asian and European origin: a pilot study of the Study of Heart Assessment and Risk in Ethnic Groups (SHARE). Clin Invest Med 1997;20:204-10.

37. Chiu M, Austin PC, Manuel DG, et al. Deriving ethnic-specific BMI cutoff points for assessing diabetes risk. Diabetes Care 2011;34:1741-8.

38. Khan NA, Wang H, Anand S, et al. Ethnicity and sex affect diabetes incidence and outcomes. Diabetes Care 2011;34:96-101.

39. Razak F, Anand SS, Shannon H, et al. Defining obesity cut points in a multiethnic population. Circulation 2007;115:2111-8.

40. Shah BR, Victor JC, Chiu M, et al. Cardiovascular complications and mortality after diabetes diagnosis for South Asian and Chinese patients: a population-based cohort study. Diabetes Care 2013;36:2670-6.

41. He M, Li ET, Harris S, et al. Canadian global village reality: anthropometric surrogate cutoffs and metabolic abnormalities among Canadians of East Asian, South Asian, and European descent. Can Fam Physician 2010;56: e174-82.

42. Gasevic D, Frohlich J, Mancini GB, et al. The association between triglyceride to high-density-lipoprotein cholesterol ratio and insulin resistance in a multiethnic primary prevention cohort. Metabolism 2012;61:583-9.

43. Mente A, Razak F, Blankenberg S, et al.; Study of the Health Assessment And Risk Evaluation in Aboriginal Peoples Investigators. Ethnic variation in adiponectin and leptin levels and their association with adiposity and insulin resistance. Diabetes Care 2010;33:1629-34.
44. Kaul P, McAlister FA, Ezekowitz JA, et al. Ethnic differences in 1-year mortality among patients hospitalised with heart failure. Heart 2011;97:1048-53.

45. García-Bailo B, Brenner DR, Nielsen D, et al. Dietary patterns and ethnicity are associated with distinct plasma proteomic groups. Am 7 Clin Nutr 2012;95:352-61.

46. Prasad GV, Vangala SK, Silver SA, et al. South Asian ethnicity as a risk factor for major adverse cardiovascular events after renal transplantation. Clin $\mathcal{F} \mathrm{Am}$ Soc Nephrol 2011;6:204-11.

47. Anand SS, Razak F, Yi Q, et al. C-reactive protein as a screening test for cardiovascular risk in a multiethnic population. Arterioscler Thromb Vasc Biol 2004;24:1509-15.

48. Anand SS, Razak F, Davis AD, et al. Social disadvantage and cardiovascular disease: development of an index and analysis of age, sex, and ethnicity effects. Int 7 Epidemiol 2006;3 5:1239-45.

49. Merchant AT, Anand SS, Vuksan V, et al. Protein intake is inversely associated with abdominal obesity in a multi-ethnic population. 7 Nutr 2005;135: 1196-201.

50. Mente A, Razak F, Blankenberg S, et al. Ethnic variation in adiponectin and leptin levels and their association with adiposity and insulin resistance. Diabetes Care 2010;33:1629-34.

51. Khan SN, Grace SL, Oh P, et al. A comparison of physical activity environments between South Asians and white Caucasians with coronary heart disease. Ethn Dis 2010;20:390-5.

52. Booth GL, Creatore MI, Moineddin R, et al. Unwalkable neighborhoods, poverty, and the risk of diabetes among recent immigrants to Canada compared with long-term residents. Diabetes Care 2013;36:302-8.

53. Banerjee AT, Grace SL, Thomas SG, et al. Cultural factors facilitating cardiac rehabilitation participation among Canadian South Asians: a qualitative study. Heart Lung 2010;39:494-503.

54. Grewal K, Leung YW, Safai P, et al. Access to cardiac rehabilitation among South-Asian patients by referral method: a qualitative study. Rebabil Nurs 2010; 35:106-12.

55. Gasevic D, Khan NA, Qian H, et al. Outcomes following percutaneous coronary intervention and coronary artery bypass grafting surgery in Chinese, South Asian and white patients with acute myocardial infarction: administrative data analysis. BMC Cardiovasc Disord 2013;13:121.

56. Bainey KR, Norris CM, Gupta M, et al. Altered health status and quality of life in South Asians with coronary artery disease. Am Heart 7 2011;162:501-6.

57. Singh N, Gupta M. Clinical characteristics of South Asian patients hospitalized with heart failure. Ethn Dis 2005;15:615-9.

58. Brister SJ, Hamdulay Z, Verma S, et al. Ethnic diversity: South Asian ethnicity is associated with increased coronary artery bypass grafting mortality. 7 Thorac Cardiovasc Surg 2007;133:150-4.

59. Improving cardiovascular disease surveillance in Canada's ethnic minority groups. Toronto: Canadian Cardiovascular Outcomes Research Team; 2012. Available: www.ccort.ca/CVDandEthnicity.aspx (accessed 2014 Mar. 1).

60. Anand SS, Razak F, Vuksan V, et al. Diagnostic strategies to detect glucose intolerance in a multiethnic population. Diabetes Care 2003;26:290-6.

61. Ivey S, Khatta M, Vedanthan R. A brown paper: the health of South Asians in the United States. Washington: South Asian Public Health Association; 2002. Available: www.sapha.org/adminkit/uploads/files/BrownPaper-CVD.pdf (accessed 2014 March 11).

62. Enas EA, Garg A, Davidson MA, et al. Coronary heart disease and its risk factors in first-generation immigrant Asian Indians to the United States of America. Indian Heart 7 1996;48:343-53.

63. Chaturvedi N. Ethnic differences in cardiovascular disease. Heart 2003;89:681-6.

64. Gupta M, Singh N, Verma S. South Asians and cardiovascular risk: what clinicians should know. Circulation 2006;113:e924-9.

65. Yajnik CS, Lubree HG, Rege SS, et al. Adiposity and hyperinsulinemia in Indians are present at birth. 7 Clin Endocrinol Metab 2002;87:5575-80.

66. Mather HM, Keen H. The Southall Diabetes Survey: prevalence of known diabetes in Asians and Europeans. Br Med 7 (Clin Res Ed) 1985;291:1081-4.

67. Anand SS, Vasudevan A, Gupta M, et al.; START Cohort Study Investigators. Rationale and design of South Asian Birth Cohort (START): a Canada-India collaborative study. BMC Public Health 2013;13:79.

68. Hughes LO, Raval U, Raftery EB. First myocardial infarctions in Asian and white men. BM7 1989;298:1345-50.

69. Mukhtar HT, Littler WA. Survival after acute myocardial infarction in Asian and white patients in Birmingham. Br Heart 7 1995; 73:122-4.

70. Wilkinson P, Sayer J, Laji K, et al. Comparison of case fatality in south Asian and white patients after acute myocardial infarction: observational study. BMF 1996;312:1330-3.

71. Tod AM, Wadsworth E, Asif S, et al. Cardiac rehabilitation: the needs of South Asian cardiac patients. Br Z Nurs 2001;10:1028-33.

72. Grunau GL, Ratner P, Hossain S. Ethnic and gender differences in perceptions of mortality risk in a Canadian urban centre. Int 7 Gen Med 2008;1:41-50.

73. Kayaniyil S, Ardern C, Winstanley J, et al. Degree and correlates of cardiac knowledge and awareness among cardiac inpatients. Patient Educ Couns 2009; 75:99-107.

74. Grewal K, Stewart DE, Grace SL. Differences in social support and illness perceptions among South Asian and Caucasian patients with coronary artery disease. Heart Lung 2010;39:180-7. 
Affiliations: Department of Clinical Epidemiology \& Biostatistics, Faculty of Health Sciences (Rana, de Souza, Kandasamy, Anand), McMaster University, Hamilton, Ont.; Chanchlani Research Centre, Department of Medicine, Faculty of Health Sciences (Rana, de Souza, Kandasamy, Anand), McMaster University, Hamilton, Ont.; Clinical Nutrition and Risk Factor Modification Centre (de Souza), St. Michael's Hospital, Toronto, Ont.; Faculty of Health Sciences (Lear), Simon Fraser University, Burnaby, BC; Division of Cardiology (Lear), Providence Health Care, Vancouver, BC; Population Health Research Institute, Hamilton Health Sciences (Anand), McMaster University, Hamilton, Ont.

Contributors: Ayesha Rana, Russell de Souza and Sonia Anand were responsible for study concept and design. Ayesha Rana, Russell de Souza, Sujane Kandasamy, Scott Lear and Sonia Anand were responsible for data acquisition. Ayesha Rana, Russell de Souza, Sujane Kandasamy and Sonia Anand analyzed and interpreted the data. Ayesha Rana, Russell de Souza, Sujane Kandasamy, Sonia Anand and Scott Lear drafted the manuscript. Ayesha Rana, Russell de Souza, Sonia Anand and Scott Lear revised the manuscript critically for important intellectual content. Ayesha Rana and Russell de Souza carried out the statistical analysis. Ayesha Rana, Russell de
Souza and Sujane Kandasamy provided administrative, technical and material support. Sonia Anand supervised the study. All authors approved the final version of this article for publication and are willing to act as guarantors of this work.

Acknowledgements: We thank Arnav Agarwal and Sonia Ruparell for their assistance with extracting data for some of the articles. We also thank Dr. Katherine Cianflone, Dr. Bibiana Garcia-Bailo and Dr. Aman Nijjar for sharing their data and additional information about the studies with us. Dr. Sonia Anand holds the Michael DeGroote Heart and Stroke Chair in Population Health, a Canada Research Chair in Ethnicity and Cardiovascular Disease and the Eli Lilly May Cohen Chair in Women's Health. Dr. Scott Lear holds the Pfizer/Heart and Stroke Foundation Chair in Cardiovascular Prevention Research at St. Paul's Hospital. Dr. Russell de Souza is a recipient of a Canadian Institutes of Health Research postdoctoral research fellowship.

Supplemental information: For reviewer comments and the original submission of this manuscript, please see www.cmajopen.ca/content $/ 2 / 3$ /E183/suppl/DC1 